ISSN 1997-342X (Online), ISSN 1991-8631 (Print)

Original Paper http://ajol.info/index.php/ijbcs http://indexmedicus.afro.who.int

\title{
Species distribution and antifungal susceptibility profile of Candida spp isolated from urine of hospitalized patients in Dschang District Hospital, Cameroon
}

\author{
Itor Alfred EKPO ${ }^{1}$, Frederick Agem KECHIA ${ }^{2,3}$, Yves Somo IWEWE ${ }^{2}$, \\ Aude Dougue NGUEGUIM ${ }^{1}$, Claude NANGWAT ${ }^{1}$ and Jean Paul DZOYEM ${ }^{1, *}$ \\ ${ }^{1}$ Department of Biochemistry, Faculty of Science, University of Dschang, P.O. Box 67, Dschang, Cameroon. \\ ${ }^{2}$ Medical/Clinical Mycology Laboratory, Faculty of Medicine and Biomedical Sciences, \\ University of Yaounde I, Cameroon. \\ ${ }^{3}$ Department of Biomedical Sciences, Faculty of Health Sciences, University of Bamenda, Cameroon. \\ "Corresponding author; E-mail: jpdzoyem@yahoo.fr; Tel.: +237676091031
}

\begin{abstract}
Candiduria refers to the presence of Candida species in urine, It is a common nosocomial infection afflicting the urinary tract. The aim of our study was to determine the prevalence of candiduria in hospitalized patients in Dschang District Hospital, and to evaluate the susceptibility patterns of Candida spp isolated from some commonly used antifungal drugs. Midstream urine samples were collected from 122 hospitalized patients at the Dschang District Hospital, then speciation of Candida was done based on colony colour on CHROMagar Candida medium. Antifungal susceptibility testing of the isolates was performed by the Broth dilution method. A total of 51 isolates of Candida species were recovered from 122 urine samples. Candida albicans was the most prevalent species $41.2 \%$ (21 isolates), followed by C. parapsilosis (27.5\%), C. glabrata (17.6\%), C. krusei (7.8\%) and C. tropicalis (5.9\%). Antifungal susceptibility test indicated that $100 \%$ and $96.1 \%$ of the Candida isolates were resistant to Amphotericin B and Nystatin respectively. Resistance varied depending on the species and the respective antifungal agents. We can conclude that candiduria is relatively common in hospitalized patients. The isolates were very resistant to polyenes (amphotericin B and nystatin) and most isolates were sensitive to azoles. Therefore, the species identification of Candida isolates along with their antifungal susceptibility pattern can help the clinicians in adequate treatment of the patients with candiduria. (C) 2017 International Formulae Group. All rights reserved.
\end{abstract}

Keywords: Candiduria, Candida spp, Hospitalized patients, Antifungal susceptibility.

\section{INTRODUCTION}

Candiduria was previously uncommon and largely ignored. Nowadays, Candida species have become an increasingly important cause of infections in humans because of the use of invasive devices, immunosuppressive therapy, and broad spectrum antimicrobial agents (Kauffman, 2014; Oubayyou et al., 2016). Since 1980s, there has been a marked increase in opportunistic fungal infections involving the urinary tract, of which Candida species are the most prevalent (Wise et al., 2000; Mogtomo et al., 2016). Several studies 
indicate that at least $10 \%-15 \%$ of hospitalacquired urinary tract infections (UTIs) are caused by Candida species and that the percentage of nosocomial UTIs due to Candida species increased from $22 \%$ for the period 1986-1989 to almost $40 \%$ for the period 1992-1997 (Richards et al., 2000; Kauffman et al., 2000; Olusegun-Joseph et al., 2016). Candiduria is the presence of Candida species in urine, particularly in hospitalized patients, especially those in the intensive care units (ICUs) who often have multiple predisposing factors which include; diabetes mellitus, indwelling urinary catheters, exposure to antimicrobial agents, cancer, long hospitalization, sex and age (Kauffman et al., 2011). Candiduria, when not properly diagnosed and treated, can lead to morbidity and mortality (Sanglard and Odds, 2002). All Candida species are capable of causing UTIs and in many centers worldwide; non-albicans Candida (NAC) species have replaced Candida albicans as the predominant pathogen. NAC species appear better adapted to the urinary tract environment and are more resistant to antifungal drugs compared with $C$. albicans (Deorukhkar et al., 2014). A study carried out by Lohoue in Yaounde, on candiduria in human immunodeficiency virus (HIV) infected patients, notified that 38 (36.2\%) out of 105 patients, comprising 25 females (65.8\%) and 13 males (34.2\%) had Candida species in their urine. Candida albicans, a saprophyte of human mucosae, was the most frequently isolated species. Some patients with candiduria were symptomatic, presenting one or several symptoms such as; fever, vulval pruritus, dysuria and severe burning sensation during (Lohoue et al., 2005). The clinical dilemma with fungal infection of the urinary tract is to distinguish between colonization and infection (Bukhary, 2008). The clinical context in this instance is invaluable in making therapeutics decisions. In the west region of Cameroon, candiduria in hospitalized patients is not closely looked at in general practice, yet it can be the source of disseminated infection in immunosuppressed patients and individuals exposed to the risk factors. In the light of foregoing, we carried out the present study to determine the prevalence of Candida species involved UTIs, and their antifungal susceptibility pattern in hospitalized patients in Dschang District Hospital.

\section{MATERIALS AND METHODS}

\section{Study design}

After receiving an Ethics clearance from the Cameroon Bioethics Initiative (Reference number CBI/340/ERCC/CAMBIN), and an authorization to carry out the study in the hospital from the Director of Dschang District Hospital (Reference: 292/AR/MSP/DRO/DSD/HDD), informed consents were sought and signed by patients from whom the urine samples were collected. Patients were made to understand that the isolates obtained from their urine samples would be used for this study. The urine samples of patients who consented to participate in the study were analyzed for yeasts, at the Laboratory of Microbiology and Antimicrobial Substances (LAMAS) of the Biochemistry Department, University of Dschang. None of the patients used antifungal drugs during the sampling process.

\section{Sample collection and mycological analysis}

After cleaning the vulva region (in females) and the tip of the penis (in males) with a dakin solution (antiseptic), midstream urine samples were collected from patients into sterile urine containers in the morning, and maintained at $4{ }^{\circ} \mathrm{C}$ during transportation to the laboratory for analysis. One hundred microliters of each uncentrifuged urine sample was cultured on CHROMagar Candida (CHROMagar Candida ${ }^{\circledR}$ ) supplemented with chloramphenicol in petri dishes and incubated 
at $25^{\circ} \mathrm{C}$ for $48 \mathrm{~h}$. The number of colonies on each petri dish was counted and recorded based on colony colors.

\section{Antifungal susceptibility test}

The susceptibility of obtained isolates was tested with four commonly used antifungal agents, namely: fluconazole, nystatin, amphotericin $\mathrm{B}$, and ketoconazole. The minimum inhibitory concentrations (MICs) were determined by means of the broth microdilution technique according to the protocol described by the National Committee for Clinical laboratory Standards (NCCLS, 2002). The number of colonies on each plate were counted and recorded based on colony colors. Since discrepancies in CFU (colony forming unit) criteria to diagnose candiduria have not yet been adequately addressed, the following CFU cut-offs were considered in this study: a quantitative culture with a colony count of $\geq 10,000 \mathrm{CFU} / \mathrm{mL}$ of urine was associated with infection while a colony count of $<10,000 \mathrm{CFU} / \mathrm{mL}$ of urine was associated with colonization (Wise et al., 2000; Kauffman, 2014). Interpretive breakpoints established by the EUCAST (2008) and Thérèse et al. (2006) were used. They were as follows: ketoconazole: Sensitive (S) $\leq 0.125 \mu \mathrm{g} / \mathrm{ml}$, Intermediate (I), 0.25-0.5 $\mu \mathrm{g} / \mathrm{ml}$, Resistant (R), $\geq 1 \mu \mathrm{g} / \mathrm{ml}$; fluconazole (S) $\leq 8 \mu \mathrm{g} / \mathrm{ml}, \quad$ (I), 16-32 $\mu \mathrm{g} / \mathrm{ml},(\mathrm{R}) \geq 64$ $\mu \mathrm{g} / \mathrm{ml}$; amphotericin $\mathrm{B}$ and nystatin $(\mathrm{S}) \leq$ $1 \mu \mathrm{g} / \mathrm{ml}$, (I), $2-4 \mu \mathrm{g} / \mathrm{ml},(\mathrm{R}) \geq 1 \mu \mathrm{g} / \mathrm{ml}$.

\section{RESULTS}

In the present study, 122 hospitalized patients in Dschang District Hospital were sampled according to Laurentz formula, $51.6 \%$ (63) were females while 48.3\% (59) were males. Their ages ranged from 2 to 60 years or more. Most of the hospitalized patients were more than 60 years old and the female gender was most represented. The prevalence of candiduria in the study population was $43.4 \%(51 / 122)$. There were $50.9 \%$ females and $40.1 \%$ males. We identified five different Candida species, namely $C$. albicans, $C$. parapsilosis, $C$. glabrata, C. krusei and C. tropicalis, present in the urine samples of the hospitalized patients group. C. albicans was the most prevalent species $41.2 \% \quad$ (21 isolates), followed by $C$. parapsilosis $(27.5 \%), C$. glabrata (17.6\%), C. krusei $(7.8 \%)$ and $C$. tropicalis $(5.9 \%)$ as shown in Figure 1. It also appears that the non-albicans Candida (NAC) species are emerging daily than the $C$. albicans species which has always remained the most prevalent. We had $58.2 \%$ of the NAC species against $41.2 \%$ of the $C$. albicans species. In our study, candiduria were also more prevalent in patients $>60$ years of age (27.45\%) followed by; $21.57 \%$ aged $15-30$ years, $19.61 \%$ aged $46-60,2-15$ years and $11.76 \%$ of age $31-45$ years (Figure 2 ).

According to the colony counts of the isolates, the Candida species isolated from the urine samples of these hospitalized patients were carried out following the standard protocol of colony forming unit per milliliter (CFU/mL of urine). We noticed a variation range of numbers with the different Candida species, C. albicans was the most prevalent in the range $<10^{4} \mathrm{CFU} / \mathrm{mL}$ of urine, seconded by C. parapsilosis and followed by $C$. glabrata. In the range of $>10^{4} \mathrm{CFU} / \mathrm{mL}$ of urine, $C$. parapsilosis was the most prevalent followed by $C$. albicans and $C$. glabrata. As shown in Figure 3. Regarding the risk factors' distribution in our study, the most prevalent risk factor was previous antibiotic therapy (32.1\%), followed by age (18.9\%) and diabetes mellitus $(15.1 \%)$ as shown in Table 1. Concerning the distribution of hospitalized patients in the different departments as shown in Table 2, the majority of the hospitalized patients positive to candiduria were in the surgical ward (50\%). C albicans, the most species isolated showed MICs values ranged 
between $0.125 \mu \mathrm{g} / \mathrm{mL}$ and $2 \mu \mathrm{g} / \mathrm{mL}$ towards ketoconazole and fluconazole as shown in Table 3. All the isolates were very resistant to polyenes $(100 \%$ of isolates for Amphotericin $\mathrm{B}$ and $96.1 \%$ of isolates Nystatin) and most isolates were sensitive to azoles with respective percentage of $30.7 \%$ for ketoconazole and $19.2 \%$ for fluconazole (Table 4). Only one isolate of Candida tropicalis was isolated and showed resistance to all the antifungal drugs tested.

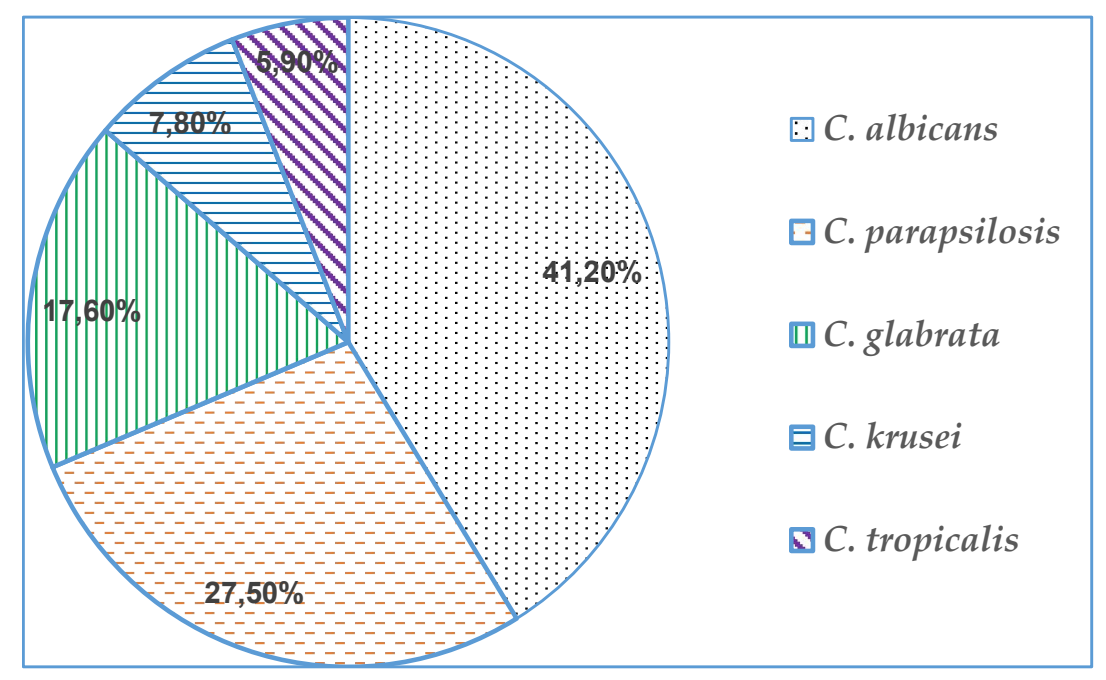

Figure 1: Distribution of Candida species identified.

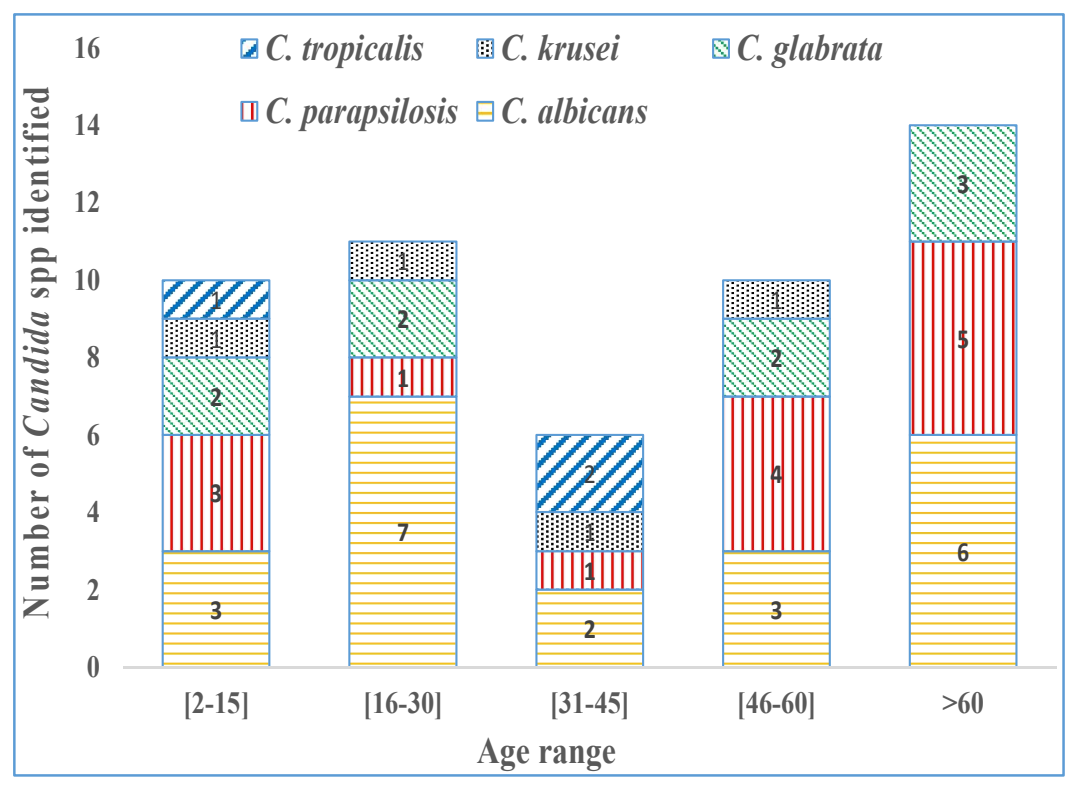

Figure 2: Candida species distribution with respect of range age. 


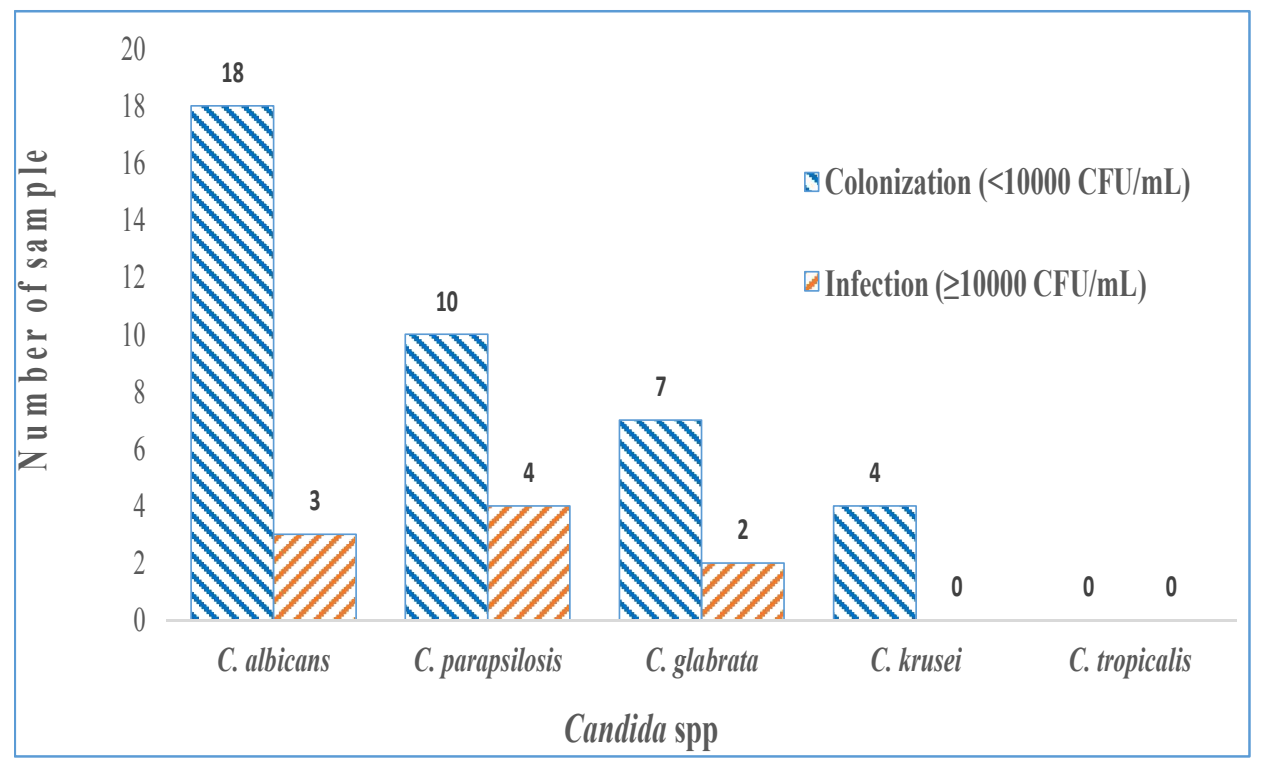

Figure 3: Candida species distribution according to the colony count.

Table 1: Distribution of candiduria according to the risk factor.

\begin{tabular}{lccc}
\hline Risk factors & Males & Females & Total \\
\hline Antibiotic & 8 & 9 & $17(32.1 \%)$ \\
Age & 6 & 4 & $10(18.9 \%)$ \\
Diabetes mellitus & 3 & 5 & $8(15.1 \%)$ \\
Long hospitalization & 2 & 4 & $6(11.3 \%)$ \\
Indwelling urinary catheter & 5 & 0 & $5(9.4 \%)$ \\
Surgical operation & 2 & 3 & $5(9.4 \%)$ \\
HIV-AIDS & 0 & 2 & $2(3.8 \%)$ \\
\hline
\end{tabular}

Table 2: Distribution of candiduria in the hospital departments.

\begin{tabular}{lccc}
\hline Departments & $\begin{array}{c}\text { Total number of } \\
\text { patients }\end{array}$ & $\begin{array}{c}\text { Number of } \\
\text { positive patients }\end{array}$ & Percentage \\
\hline Male ward & 41 & 17 & $41.4 \%$ \\
Female ward & 37 & 18 & $48.6 \%$ \\
Pediatric & 21 & 5 & $23.8 \%$ \\
Surgical ward & 18 & 9 & $50 \%$ \\
Up standing & 5 & 2 & $40 \%$ \\
Total & $\mathbf{1 2 2}$ & $\mathbf{5 1}$ & $\mathbf{4 1 . 8 \%}$ \\
\hline
\end{tabular}


Table 3: Minimum inhibitory concentration (MICs) values of antifungals tested on Candida spp isolates.

\begin{tabular}{lcccccc}
\hline \multirow{2}{*}{ Antifungals } & \multicolumn{5}{c}{ MIC $(\boldsymbol{\mu g} / \mathbf{m L})$} \\
\cline { 2 - 7 } Ketoconazole & Range & $0.125-2$ & $0.125-4$ & $34->256$ & $1->256$ & $>256$ \\
& GM & 0.45 & 0.74 & $>12.12$ & $>12.12$ & $>256$ \\
Fluconazole & Range & $0.125-2$ & $8-64$ & $1->256$ & $<0.125-2$ & $>256$ \\
\multirow{2}{*}{ Nystatin } & GM & 17.44 & 26.25 & $>111.43$ & $<0.87$ & $>256$ \\
& Range & $4->256$ & $>256$ & $>256$ & $>256$ & $>256$ \\
Amphotericin B & GM & $>14.67$ & $>256$ & $>256$ & $>256$ & $>256$ \\
& Range & $>256$ & $>256$ & $>256$ & $>256$ & $>256$ \\
& GM & $>256$ & $>256$ & $>256$ & $>256$ & $>256$ \\
\hline GM: Geometric mean, Ca: Candida albicans, Cp: Candida parapsilosis, Cg: Candida glabrata, Ck: Candida krusei,
\end{tabular}

Cd: Candida dubliniensis, $\mathrm{n}=$ number of isolate tested.

Table 4: Antifungal susceptibility profiles of Candida spp identified against ketoconazole, fluconazole, nystatin and amphotericin B.

\begin{tabular}{lccccccc}
\hline Antifungals & & $\boldsymbol{C a}(\mathbf{n}=\mathbf{8})$ & $\boldsymbol{C} \boldsymbol{p}(\mathbf{n}=\mathbf{7})$ & $\boldsymbol{C g}(\mathbf{n}=\mathbf{5})$ & $\boldsymbol{C} \boldsymbol{k}(\mathbf{n}=\mathbf{5})$ & $\boldsymbol{C t}(\mathbf{n}=\mathbf{1 )}$ & Total \\
\hline \multirow{3}{*}{ Ketoconazole } & $\mathrm{S}$ & $3(37.7 \%)$ & $2(28.5 \%)$ & $2(40 \%)$ & $1(20 \%)$ & $0(0 \%)$ & $8(30.7 \%)$ \\
& $\mathrm{I}$ & $2(25 \%)$ & $1(14.2 \%)$ & $0(0 \%)$ & $1(20 \%)$ & $0(0 \%)$ & $4(15.3 \%)$ \\
& $\mathrm{R}$ & $3(37.7 \%)$ & $4(57.1 \%)$ & $3(60 \%)$ & $3(60 \%)$ & $1(100 \%)$ & $14(53.8 \%)$ \\
Fluconazole & $\mathrm{S}$ & $4(50 \%)$ & $1(28.5 \%)$ & $0(0 \%)$ & $0(0 \%)$ & $0(0 \%)$ & $5(19.2 \%)$ \\
& $\mathrm{I}$ & $2(25 \%)$ & $3(42.8 \%)$ & $2(40 \%)$ & $2(40 \%)$ & $0(0 \%)$ & $9(34.6 \%)$ \\
& $\mathrm{R}$ & $2(25 \%)$ & $3(42.8 \%)$ & $3(60 \%)$ & $3(60 \%)$ & $1(100 \%)$ & $11(42.3 \%)$ \\
Nystatin & $\mathrm{S}$ & $0(0 \%)$ & $0(0 \%)$ & $0(0 \%)$ & $0(0 \%)$ & $0(0 \%)$ & $0(0 \%)$ \\
& $\mathrm{I}$ & $1(12.5 \%)$ & $0(0 \%)$ & $0(0 \%)$ & $0(0 \%)$ & $0(0 \%)$ & $1(3.8 \%)$ \\
& $\mathrm{R}$ & $7(87.5 \%)$ & $7(100 \%)$ & $5(100 \%)$ & $5(100 \%)$ & $1(100 \%)$ & $25(96.1 \%)$ \\
Amphotericin $\mathrm{B}$ & $\mathrm{I}$ & $0(0 \%)$ & $0(0 \%)$ & $0(0 \%)$ & $0(0 \%)$ & $0(0 \%)$ & $0(0 \%)$ \\
& $\mathrm{I}$ & $0(0 \%)$ & $0(0 \%)$ & $0(0 \%)$ & $0(0 \%)$ & $0(0 \%)$ & $0(0 \%)$ \\
& $\mathrm{R}$ & $8(100 \%)$ & $7(100 \%)$ & $5(100 \%)$ & $5(100 \%)$ & $1(100 \%)$ & $26(100 \%)$ \\
\hline
\end{tabular}

S: susceptible, I: intermediate, R: resistant, Ca: Candida albicans, Ck: Candida krusei, Cg: Candida glabrata, Cp: Candida parapsilosis, $C d$ : Candida dubliniensis, $\mathrm{n}=$ number of isolate tested.

\section{DISCUSSION}

This study identified five different species of Candida yeasts that cause infections among patients who are hospitalized in Dschang District Hospital. About $41.18 \%$ of the culture from sampled patients yielded different species of Candida, in which the non-albicans Candida were more prevalent than Candida albicans. However, several reports show that NAC species, especially C. tropicalis, C. glabrata and C. parapsilosis now predominate in many regions (Kaur et al., 2007). Our study reports a $58.82 \%$ prevalence of the non-albicans species and a $41.18 \%$ prevalence of albicans species as shown in Table 2, corroborating with the results of many similar previous studies, especially that of Jain et al. (2007). In 
this study, candiduria was more prevalent in the age range greater than 60 years $(27.7 \%)$ followed by $21.57 \%$ of age $15-30$ years. According to this, candiduria was found to be more frequent in elderly patients. Similar observation was previously made by Hassaneen et al. (2014) who reported a highest percentage of positive cases of candiduria among those in the older age group. Several reports show that the frequency of candiduria in women is more than that in men (Kobayashi et al., 2012) and this corroborated with our study. Candiduria accounted for up to $10 \%$ of UTIs and has resulted in increased rate of mortality during the last decades, due to use of new medical instruments, surgery and transplantation (Nayman et al., 2011). According to Weinberger et al. (2003), prolonged hospitalization and long antibiotics use increase candiduria in patients. This correlates with our study in which candiduria was more prevalent in patients who were on antibiotic treatment. These results corroborated with those of Zarei-Mahmoudabadi et al. (2012) who found that he major predisposing factor associated with candiduria was prolonged antibiotic therapy (69.1\%). However, there is little or no evidence that supports the fact that systemic antibiotics directly influence Candida species proliferation or virulence. It is likely that antibiotics contribute to the colonization by Candida species by suppressing endogenous bacterial flora, primarily in the gut and lower genital tract, and possibly, superficial areas adjacent to the urethral meatus (Fisher et al., 1995). The majority of the hospitalized patients positive to candiduria were in the surgical ward $(50 \%)$. It has been reported that, the most common risk factors for candiduria is in hospitalized patients (Goetz et al., 2010). In this study, $82.35 \%$ of patients had colonization. However, $17.64 \%$ of diabetic patients had infection which could be due to their increased tissue glucose level, facilitating the growth of Candida. Our finding is close to that reported by Seifi et al. (2013) who found an infection rate of $14.3 \%$ in children in Ahvaz.

\section{Antifungal susceptibility profile of the isolates}

Antifungal susceptibility of 26 Candida yeast isolates to fluconazole, ketoconazole, nystatin and amphotericin B was determined using the broth dilution method. The results showed that the susceptibility of 26 isolates of Candida species that were tested against frequently used antifungal drugs has various degrees. The isolates were very resistant to polyenes (amphotericin B and nystatin) and most isolates were sensitive to azoles (fluconazole and ketoconazole). Candida albicans, the most species isolated, showed some various degree of susceptibility against azole antifungals tested. Sensitivity to ketoconazole and fluconazole was $37.7 \%$, and $50 \%$ respectively with respective geometric mean values of $0.45 \mu \mathrm{g} / \mathrm{mL}$ and $17.44 \mu \mathrm{g} / \mathrm{mL}$. All the isolates were resistant to amphotericin B. Except for $C$ albicans which revealed an intermediate susceptibility against nystatin, all other Candida species showed resistance. This observation is uncommon compared with almost all the previously reported studies that indicated some degree of sensitivity to amphotericin B. Although, in a study conducted by Ruan et al. (2008), the resistance was extremely high against amphotericin B in C. krusei strains (95\%) and in C. glabrata strains (53\%), in recent years, the low rates of amphotericin $B$ resistance have been reported in the $C$. albicans, $C$. glabrata, C. parapsilosis, C. tropicalis and $C$. krusei isolates (Metin et al., 2011; Taj-Aldeen et al., 2014).

\section{Conclusion}

In conclusion, the prevalence of candiduria in hospitalized patients at the 
Dschang District Hospital was $41.8 \%$, and $C$ albicans was the most prevalent yeast isolated. All the isolates showed uncommon high percentage of resistance against polyenes antifungals (amphotericin B and nystatin) and most of the isolates were sensitive to azoles. Therefore, species definition and determination of antifungal susceptibility patterns are recommended for the proper management and treatment of patients at risk for candidiasis. Resistance to antifungal agents is an alarming sign for the emerging common nosocomial fungal infections.

\section{COMPETING INTERESTS}

The authors declare that they have no competing interests.

\section{AUTHORS' CONTRIBUTIONS}

ISY, FAK and JPD conceived and designed the experiments; AND, IAE and CN performed the experiments; ISY, CN and IAE analyzed the data; AND and CN drafted the manuscript and JPD finalized the paper.

\section{ACKNOWLEDGEMENTS}

JPD is thankful to "The World Academy of Sciences (TWAS) for the advancement of science in developing countries" and to Committee on Scientific and Technological Cooperation (COMSTECH) for the (COMSTECH)-TWAS Joint Research Grants Programme awarded to provide equipment used for this work.

\section{REFERENCES}

Bukhary ZA. 2008. Candiduria: a review of clinical significance and management. Saudi J. Kidney Dis. Transpl., 19(3): 350-60.

DOI:

http://www.sjkdt.org/text.asp? 2008/19/3/350/ 40493.

Deorukhkar SC, Saini S, Mathew S. 2014. Non-albicans Candida infection: An emerging threat. Interdiscip. Perspect.
Infect. Dis., 2014: 615958. DOI: 10.1155/2014/615958.

Fisher JF, Newman CL, Sobel J D. 1995. Yeast in the urine: solutions for a budding problem. Clin Infect Dis., 20(1): 183-9. DOI: http://www.jstor.org/stable/ 4458292.

Goetz LL, Howard M, Cipher D, Revankar SG. 2010. Occurrence of candiduria in a population of chronically catheterized patients with spinal cord injury. Spinal Cord., 48(1): 51-54. DOI: 10.1038/sc.2009.81.

Hassaneen AM, Ghonaim RA, Hassanin HM, Salama NA, Elgohary T. 2014. Different aspects of candiduria as an important nosocomial infection. Med. J. Cairo Univ., 82(1): 199-204.

Jain N, Kohli R, Cook E, Gialanella P, Chang T, Fries BC. 2007. Biofilm formation by and antifungal susceptibility of Candida isolates from urine. Appl. Environ. Microbiol., $\quad$ 73(6): 1697-703. DOI:10.1128/AEM.02439-06.

Kauffman CA, Fisher JF, Sobel JD, Newman CA. 2011. Candida urinary tract infections--diagnosis. Clin. Infect. Dis., 52(6): S452-S456. DOI: 10.1093/cid/cir111.

Kauffman CA, Vazquez JA, Sobel JD, Gallis HA, McKinsey DS, Karchmer AW, Sugar AM, Sharkey PK, Wise GJ, Mangi R, Mosher A, Lee JY, Dismukes WE. 2000. Prospective multicenter surveillance study of funguria in hospitalized patients. The National Institute for Allergy and Infectious Diseases (NIAID) Mycoses Study Group. Clin. Infect. Dis., 30(1):14-8. DOI: $10.1086 / 313583$.

Kauffman CA. 2005. Candiduria. Clin. Infect. Dis., 41(6): S371-6. DOI: https://doi.org/10.1086/430918.Kauffma n CA. 2014. Diagnosis and management of fungal urinary tract infection. Infect. 
Dis. Clin. North. Am., 28(1):61-74. DOI: 10.1016/j.idc.2013.09.004.

Kaur R, Dhakad MS, Goyal R, Kumar R. 2016. Emergence of non-albicans Candida species and antifungal resistance in intensive care unit patients. Indian. J. Microbiol. Res., 3(4): 398-400. DOI: https://doi.org/10.1016/ j.apjtb.2015.12.019.

Kobayashi C, de Fernandes F, Miranda C, de Sousa D, Silva R. 2004. Candiduria in hospital patients: a study prospective. Mycopathologia, 158(1):49-52. DOI: 10.1023/B:MYCO.0000038436.51918.d 9.

Lohoue J, Angwafo FF, Kechia F and Noukeu N. 2005. Candiduria in HIV infected patients in Yaoundé, Cameroon. Afr. J. Urol., 11(1): 61-5.

Metin DY, Hilmioglu-Polat S, Samlioglu P, Doganay-Oflazoglu B, Inci R, Tumbay E. 2011. Evaluation of antifungal susceptibility testing with microdilution and Etest methods of Candida blood isolates. Mycopathologia, 172(3): 18799. DOI: 10.1007/s11046-011-9413-y.

Mogtomo KML, Njiki NA, Longang A-M, Foko LPK, Embolo E, Kom B, Wandja PV, Tchamdjeu F, Ngono NAR. 2016. Prévalence des germes impliqués dans les infections vaginales chez les femmes camerounaises et facteurs de risque. Int. J. Biol. Chem. Sci., 10(1): 255-268. DOI: http://dx.doi.org/10.4314/ijbcs.v10i1.20.

National Commitee for Clinical Laboratory Standards. Reference method for broth dilution antifungal susceptibility testing of yeasts. Approved standard (NCCLS document M27-A2) Villanova, PA: National Committee for Clinical Laboratory Standards. 2002.

Nayman AS, Özguneş I, Ertem OT, Erben N, Doyuk Kartal E, Tözun M, Usluer G. 2011. Evaluation of risk factors in patients with candiduria. Mikrobiyol. Bul., 45(2): 318-324.
Olusegun-Joseph TS, Killaney VM. 2016. Survey of possible pathogenic organisms found in urine and vaginal swab samples of selected female population in Lagos, Nigeria. Int. J. Biol. Chem. Sci., 10(4): 1840-1852. DOI: http://dx.doi.org/ 10.4314/ijbcs.v10i4.32.

Oubayyou AM, Zida A, Moumouni H, Savadogo A, Traore AS, Ouedraogo M. 2016. Aspects épidémiologiques et étiologiques des affections pulmonaires d'origine parasitaire et fongique en milieu hospitalier à Ouagadougou (Burkina Faso). Int. J. Biol. Chem. Sci., 10(3): 1286-1294. DOI: http://dx.doi.org/10.4314/ijbcs.v10i3.30.

Richards MJ, Edwards JR, Culver DH, Gaynes RP. 2000. Nosocomial infections in combined medical-surgical intensive care units in the United States. Infect. Control Hosp. Epidemiol., 21(8): 510-5. DOI: $10.1086 / 501795$.

Ruan SY, Chu CC, Hsueh PR. 2008. In vitro susceptibilities of invasive isolates of Candida species: rapid increase in rates of fluconazole susceptible-dose dependent Candida glabrata isolates. Antimicrob. Agents Chemother., 52(8): 2919-22. DOI: 10.1128/AAC.00323-08.

Sanglard D, Odds F C. 2002. Resistance of Candida species to antifungal agents: molecular mechanism and clinical consequences. Lancet Infect. Dis., 2(2): 73-85.

DOI: https://doi.org/10.1016/S14733099(02)00181-0.

Seifi Z, Azish M, Salehi Z, Mahmoudabadi AZ, Shamsizadeh A. 2013. Candiduria in children and susceptibility patterns of recovered Candida species to antifungal drugs in Ahvaz. J. Nephropathology., 2(2): $122-128$. DOI:10.12860/JNP.2013.20.

Sobel J, Fisher JF, Kauffman CA, Newman CA. 2011. Candida urinary tract infections--epidemiology. Clin. Infect. 
Dis., $52 \quad$ (6): $\quad$ S433-S436. DOI: 10.1093/cid/cir109.

Subcommittee on Antifungal Susceptibility Testing of the ESCMID European Committee for Antimicrobial Susceptibility Testing. (EUCAST). 2008. Technical Note on the method for the determination of broth dilution minimum inhibitory concentrations of antifungal agents for conidia-forming moulds. Clin. Microbiol. Infect., 14: 982-4. DOI: http://dx.doi.org/10.1111/j.14690691.2008.02086.x.

Taj-Aldeen SJ, Kolecka A, Boesten R, Alolaqi A, Almaslamani M, Chandra P, Meis JF, Boekhout T. 2014. Epidemiology of candidemia in Qatar, the Middle East: performance of MALDI-TOF MS for the identification of Candida species, species distribution, outcome, and susceptibility pattern. Infection, 42(2): 393-404. DOI: 10.1007/s15010-0130570-4.

Thérèse L, Bagyalakshmi R, Madhavan N, Deepa P. 2006. In vitro suscepbility testing by agar dillution method to determine the minimum inhibitory concentrations of amphotericin B, fluconazole and ketoconazole agains ocular fungal isolates. Indian $\mathrm{J}$. Med. Microbiol., 24(4): 273-9. DOI: 10.4103/0255-0857.29386.

Weinberger M, Sweet S, Leiboviciy L, Pitlik SD, Samraz Z. 2003. Correlation between candiduria and departmental antibiotic use. J. Hosp. Infect., 53(3):183-186. DOI: https://doi.org/10.1053/jhin.2002.1354.

Wise J, Goldberg F, Kozinn J. 2000. Genitourinary candidiasis: diagnosis and treatment. J. Urol., 116(6): 778-780.

Zarei-Mahmoudabadi A, Zarrin M, Ghanatir F, Vazirianzadeh B. 2012. Candiduria in hospitalized patients in teaching hospitals of Ahvaz. Iran J. Microbiol., 4(4): $\quad$ 198-3. $\quad$ DOI: http://ijm.tums.ac.ir/index.php/ijm/article /view/671. 